\title{
Synthesis, Molecular Docking and Biological Evaluation of Some New Benzotriazines
}

\author{
Samir M. El Rayes ${ }^{1 *}$, Ibrahim A. I. Ali. ${ }^{1}$, Walid Fathalla ${ }^{2}$, Mostafa A. A. \\ Mahmoud $^{1}$ \\ ${ }^{1}$ Department of Chemistry, Faculty of Science, Suez Canal University, Ismailia, Egypt. \\ ${ }^{2}$ Physics and Math. Engineering Department, Faculty of Engineering, Port-Said University, Port Said, \\ Egypt. https://orcid.org/0000-0002-7769-4042
}

\begin{abstract}
.
Methyl 2-(4-oxobenzotriazin-3(4H)-yl) alkanoates4a-c proved to be important intermediates for the preparation of some biologically interesting compounds containing the benzotriazinone ring system. Esters 4a-c were prepared by direct diazotization of methyl anthranilate followed by addition of amino acid esters hydrochloride in a one-pot strategy. An equivocal synthesis of methyl 2-(4oxobenzotriazin-3(4H)-yl) acetate 4a was achieved by alkylation of benzotriazin-4(3H)one with methyl chloroacetate on the basis of chemoselective reaction of heterocyclic amide with electrophiles.
\end{abstract} A series of $N$-alkyl-2-(4-oxobenzotriazin-3(4H)-yl) alkanamides7-8(a-h) and methyl 2-(2-(4oxobenzotriazin-3(4H)-yl)alkanamido)alkanoates (dipeptides) 9-10(a-d) were prepared via azide coupling from $\mathbf{4 a - b}$. Esters $\mathbf{4 a - b}$ were converted into the corresponding hydrazides followed by condensation with aldehydes; 4-methoxybenzaldehyde, 4-dimethylamino benzaldehyde and arabinose to afford the corresponding hydrazone derivatives11-13. All the synthesized compounds were subjected to the molecular docking using MOE 2008-10 software as agonist for; E. coli Fab-H receptor and Vitamin D receptor for antibacterial and anticancer evaluation, respectively. The most pronounced strong binding affinity towards the target E. coli Fab-H receptor were compounds 7a, 11a, 11b,10a,10cand 12b. On the other hand, the most pronounced strong binding affinity towards the target Vitamin D receptor were compounds 3, 9c, 11a and 10d. The in vitro antibacterial activity of highest binding affinity docked compounds were tested against E. coli, Staphylococcus aureus and Salmonella spp. All the tested compounds gave effective positive results against E. coli with inhibitory zone of about $1.1 \mathrm{~cm}$, while were inactive against Staphylococcus aureus and Salmonella spp. The in vitro cytotoxic activity of the highest binding affinity docked compounds were tested against human liver carcinoma cell line (HepG2) cancer cell lines. Many compounds showed 
potent cytotoxic activity with low $\mathrm{IC}_{50}$ values, especially for $3(6.525 \mu \mathrm{M})$ and 11a $(10.97 \mu \mathrm{M})$, while for standard drug doxorubicin $(5.8 \mu \mathrm{M})$.

\section{Keywords}

Benzotriazinone, Amino acid, Amines, Hydrazones, Docking, Antibacterial, Anticancer activity, Human liver carcinoma cell line HepG2, dipeptides, amino acid carboxamides

\section{1- Introduction}

One of the most corner stone principles in our research group is based on searching for new anticancer drugs $^{1,2}$ where the search for new anticancer drugs is never ending task with the aim to obtain products with lower toxicity and more selectivity towards tumor cells. Benzotriazine and its derivatives possess a diverse range of biological activities of pharmacological activities including antimicrobial, ${ }^{3}$ antiinflammatory ${ }^{4}$, anti-depressant ${ }^{5}$, anti-ulcer ${ }^{6}$, antidiarrhoeal ${ }^{7}$, anaesthetics ${ }^{8}$, anticancer ${ }^{9}$. Some current commercial benzotriazinone anticancer drugs such as $\alpha$-hydroxylatedbenzotriazinone ${ }^{10}, N$ Arylbenzotriazinones ${ }^{11,12}, \quad$ Tirapazamine(1,2,4-benzotriazin-3-amine,1,4-dioxide) ${ }^{13}$ and $4-[(4-$ Oxobenzotriazin-3(4H)-yl)methyl]benzoic acid $^{14}$ show the possibility to reduce recombinant human cancer cells growth in culture.<smiles>O=C1NN(O)Nc2ccccc21</smiles>

2-hydroxy benzotriazinone<smiles>Nc1n[n+]([O-])c2ccccc2[n+]1[O-]</smiles>

C

\section{1,2,4-benzotriazin-} 3-amine, 1,4-dioxide<smiles>[R]c1cccc(NNC(=O)c2ccccc2NC)c1</smiles>

B

$\mathrm{N}$-aryl benzotriazinone<smiles>O=C(O)c1ccc(Cn2nnc3ccccc3c2=O)cc1</smiles>

D

4-[(4-Oxobenzo[d]][1,2,3]triazin$3(4 \mathrm{H})$-yl)methyl]benzoic acid

Figure 1. Some current commercial benzotriazinone anticancer drugs.

Beside the established applications of benzotriazin-4(3H)-one in dying, ${ }^{15}$ imaging and recording material. $^{16}$ One of the most important benzotriazin-4(3H)-one derivative is 3-Hydroxy-1,2,3benzotriazin-4(3H)-one where it is a versatile reagent employed for peptide synthesis. ${ }^{17}$ 
In the present work, we aimed to synthesize a series of compounds containing benzotriazinone moiety on the basis of structure modification of methyl 2-(4-oxobenzotriazin-3(4H)-yl) alkanoates 4a-c for biological evaluation as antimicrobial and anticancer agents.

\section{2- Discussion.}

Early attempts for preparation of $\mathbf{4 a - c}$ as the target molecules for structure modification of benzotriazinone was achieved from isatoic anhydride 1. Isatoic anhydride1 was reacted with ammonia in the presence of ammonium carbonate to give anthranilamide 2 , which subsequently diazotized using sodium nitrite and $\mathrm{HCl}$ solution at $0^{\circ} \mathrm{C}$ to give benzotriazinone 3 . The benzotriazinone 3 was reacted with methyl chloroacetate in DMF in the presence of potassium carbonate at $100^{\circ} \mathrm{C}$ to give the chemoselective $\mathrm{N}$-alkylated ester; methyl 2-(4-oxobenzotriazin-3(4H)-yl) acetate $\mathbf{4 a}$ as the only product on the basis of chemoselective reactivity of heterocyclic amides towards electrophiles, Scheme ${ }^{18,19}$. The multi-step reactions mentioned gave 4a in an overall high yield from available isatoic anhydride but the alkyl halides needed to prepare other methyl 2-(4-oxobenzotriazin-3(4H)-yl) alkanoates 4a-c were not available.<smiles>O=c1[nH]c2ccccc2c(=O)o1</smiles>

1<smiles>NC(=O)ONC(=O)O</smiles>

$\left(\mathrm{NH}_{4}\right)_{2} \mathrm{CO}_{3} / \mathrm{NH}_{4} \mathrm{Cl}$<smiles>CC(C)C(C)(C)[N+](=O)[O-]</smiles><smiles>COC(=O)Cn1nnc2ccccc2c1=O</smiles>

$4 a$<smiles>O=c1[nH]nnc2ccccc12</smiles>

3

Scheme 1. Multi-step method for preparation of methyl 2-(4-oxobenzotriazin-3(4H)-yl) acetate 4a.

Diazotization of methyl anthranilate 3 using sodium nitrite and $\mathrm{HCl}$ solution at $0^{\circ} \mathrm{C}$ followed by addition of amino acid ester hydrochloride in the presence of triethyl amine in a one pot strategy afforded methyl 2-(4-oxobenzotriazin-3(4H)-yl) alkanoates4a-c in excellent yields, Scheme 2. This method has the advantage of simple work up, one pot and the availability of reagents. 


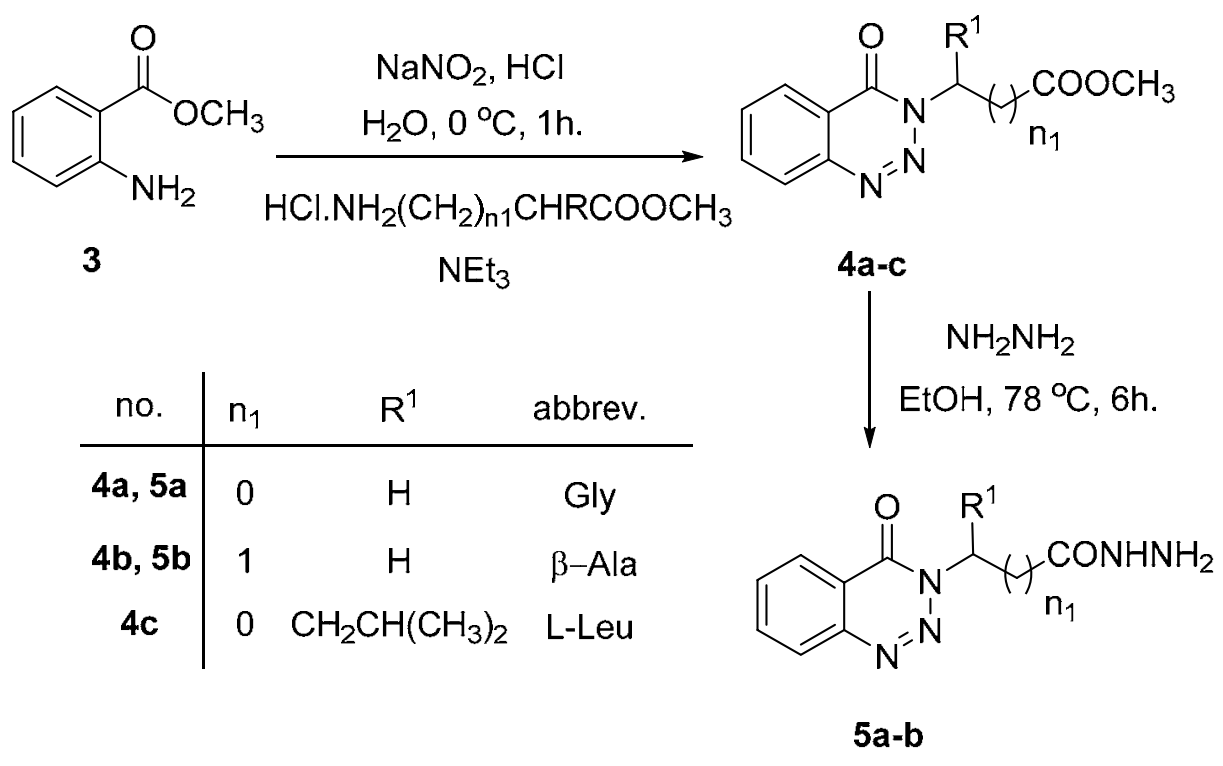

Scheme 2. Direct preparation of methyl 2-(4-oxobenzotriazin-3(4H)-yl) alkanoates 4a-c.

The structure assignment of methyl 2-(4-oxobenzotriazin-3(4H)-yl) alkanoates 4a-c is based on full characterization, including ${ }^{1} \mathrm{H}$ and ${ }^{13} \mathrm{C}$ NMR spectroscopy. Thus, the ${ }^{1} \mathrm{H}$ NMR spectrum of methyl 3(4-oxobenzotriazin-3(4H)-yl)propanoate $4 \mathbf{b}$ revealed signals at $\delta$ 4.73-4.68, 3.65 and 2.95-2.89ppm for $\mathrm{OCH}_{3}, \mathrm{NCH}_{2}$ and $\mathrm{CH}_{2} \mathrm{CO}$ groups respectively. The ${ }^{13} \mathrm{C}$ NMR spectrum of $\mathbf{4 b}$ showed signals at $\delta$ 171.0, 155.3, 51.9, 45.5 and $33.0 \mathrm{ppm}$ for $2 \mathrm{C}=\mathrm{O}$ groups, $\mathrm{OCH}_{3}, \mathrm{NCH}_{2}$ and $\mathrm{CH}_{2} \mathrm{CO}$ groups, respectively.

Methyl2-(4-oxobenzotriazin-3(4H)-yl)alkanoates 4a-c are excellent precursors for structure modification of benzotriazinone ring system via azide coupling method by an attachment of either amines or amino acid through a peptide bond. Thus, the ester $\mathbf{4 a - b}$ reacted with hydrazine hydrate in ethanol under reflux condition for $6 \mathrm{~h}$ afforded the corresponding hydrazides $\mathbf{5 a , b}$, Scheme2. Hydrazides 5a,b were reacted with $\mathrm{NaNO}_{2}$ and $\mathrm{HCl}$ in water at $0{ }^{\circ} \mathrm{C}$ for $1 \mathrm{~h}$. to afford the corresponding azides $\mathbf{6 a , b}$ and were extracted with ethyl acetate. The insitu generated azide $\mathbf{6 a , b}$ solution was successively added to primary amines; isopropyl, n-butyl, tert-butyl, n-decyl, cyclohexyl and benzyl amines and secondary amines; piperidine and morpholine to give $\mathrm{N}$-alkyl-2-(4oxobenzotriazin-3(4H)-yl) alkanamides7-8(a-h) in good yields, Scheme 3. 


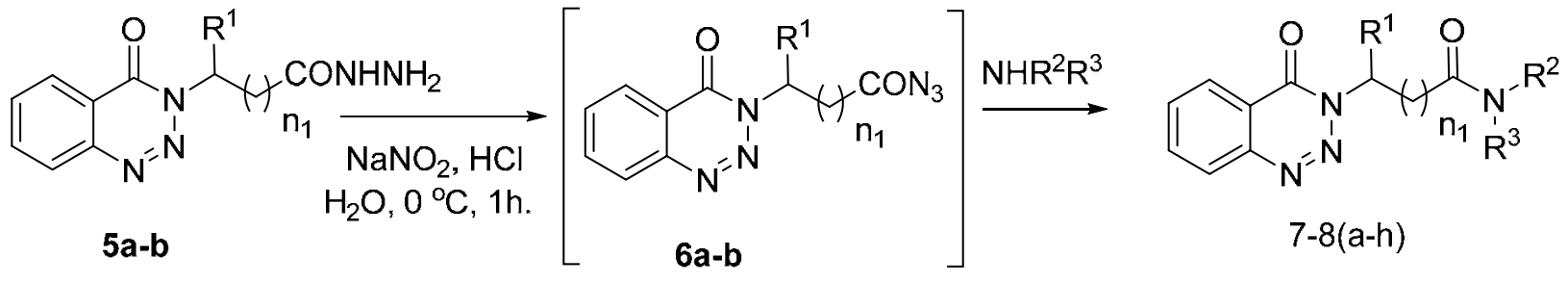

\begin{tabular}{|c|c|c|c|c|c|c|c|}
\hline no. & $\mathrm{n}_{1}$ & $\mathrm{R}^{1}$ & $N R^{1} R^{2}$ & no. & $\mathrm{n}_{1}$ & $\mathrm{R}^{1}$ & $N R^{1} R^{2}$ \\
\hline $7 a$ & 0 & $\mathrm{H}$ & $\mathrm{NHCH}\left(\mathrm{CH}_{3}\right)_{2}$ & $8 a$ & 1 & $\mathrm{H}$ & $\mathrm{NHCH}\left(\mathrm{CH}_{3}\right)_{2}$ \\
\hline $7 b$ & 0 & $\mathrm{H}$ & $\mathrm{NH}\left(\mathrm{CH}_{2}\right)_{3} \mathrm{CH}_{3}$ & $8 b$ & 1 & $\mathrm{H}$ & $\mathrm{NH}\left(\mathrm{CH}_{2}\right)_{3} \mathrm{CH}_{3}$ \\
\hline $7 c$ & 0 & $\mathrm{H}$ & $\mathrm{NHCH}\left(\mathrm{CH}_{3}\right)_{3}$ & $8 c$ & 1 & $\mathrm{H}$ & $\mathrm{NHCH}\left(\mathrm{CH}_{3}\right)_{3}$ \\
\hline $7 d$ & 0 & $\mathrm{H}$ & $\mathrm{NH}\left(\mathrm{CH}_{2}\right)_{9} \mathrm{CH}_{3}$ & $8 d$ & 1 & $\mathrm{H}$ & $\mathrm{NH}\left(\mathrm{CH}_{2}\right)_{9} \mathrm{CH}_{3}$ \\
\hline $7 e$ & 0 & $\mathrm{H}$ & $\mathrm{HI}$ & $8 e$ & 1 & $\mathrm{H}$ & \\
\hline $7 f$ & 0 & $\mathrm{H}$ & & $8 f$ & 1 & $\mathrm{H}$ & \\
\hline $7 \mathrm{~g}$ & 0 & $\mathrm{H}$ & $\mathrm{N}$ & $8 g$ & 1 & $\mathrm{H}$ & \\
\hline $7 \mathrm{~h}$ & 0 & $\mathrm{H}$ & $N$ & $8 \mathrm{~h}$ & 1 & $\mathrm{H}$ & IV \\
\hline
\end{tabular}

Scheme 3. Azide coupling method for the preparation of $\mathrm{N}$-alkyl-2-(4-oxobenzotriazin-3(4H)-yl) alkanamides 7-8(a-h).

Next, the insitu generated azide 6a,b solution was simultaneously added to amino acid methyl ester hydrochloride; glycine, L-leucine and L-tryptophane to give methyl 2-(2-(4-oxobenzotriazin-3(4H)yl)alkanamido)alkanoates (dipeptides) 9-10 (a-d) in good yields via azide coupling method, Scheme4.

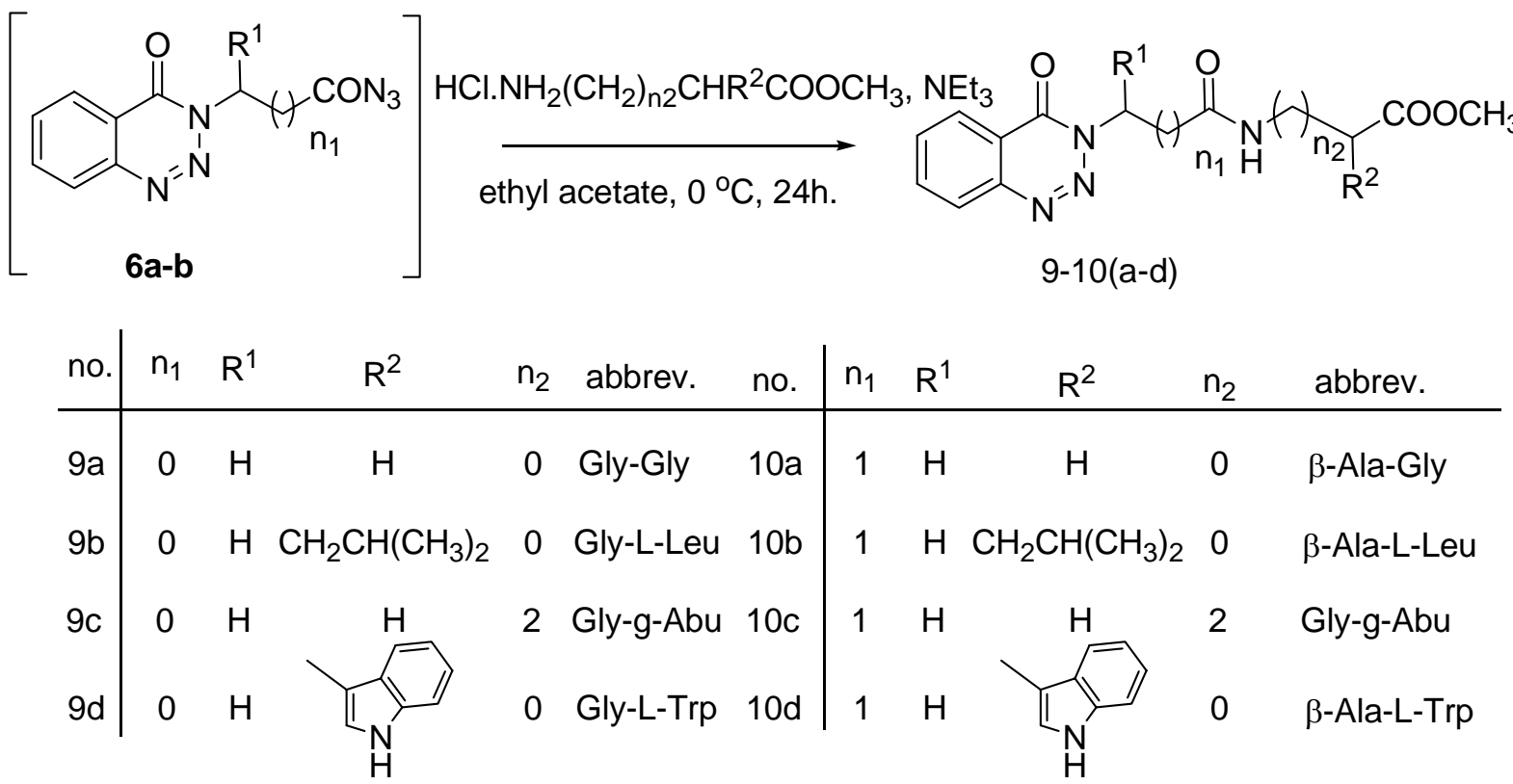

Scheme 4. Azide coupling method for the preparation of methyl 2-(2-(4-oxobenzotriazin-3(4H)yl)alkanamido) alkanoates (dipeptides) 9-10(a-d). 
The structure assignment of $\mathrm{N}$-alkyl-2-(4-oxobenzotriazin-3(4H)-yl) alkanamides 7-8(a-h)and give methyl 2-(2-(4-oxobenzotriazin-3(4H)-yl)alkanamido) alkanoates (dipeptides)9-10(a-c) is based on full characterization, including ${ }^{1} \mathrm{H}$ and ${ }^{13} \mathrm{C}$ NMR spectroscopy. Thus, the ${ }^{1} \mathrm{H}$ NMR spectrum of methyl 2-(2-(4-oxobenzotriazin-3(4H)-yl)acetamido) acetate 9a showed signals at $\delta 5.22,4.14$, and $3.77 \mathrm{ppm}$ corresponding to $\mathrm{NCH}_{2}, \mathrm{NHCH}_{2}$ and $\mathrm{OCH}_{3}$, respectively. The ${ }^{13} \mathrm{C} \mathrm{NMR}$ spectrum of 9a showed signals at $170.1,166,3,155.9,52.6,52.5$ and 41.4 ppm for $3 \mathrm{C}=\mathrm{O}$ groups, $\mathrm{OCH}_{3}, \mathrm{NCH}_{2}$ and $\mathrm{NHCH}_{2}$ groups, respectively.

Next, a number of hydrazones 11-12(a,b) was prepared by condensation of hydrazides 5a,b with aldehydes; 4-methoxybenzaldehyde and 4-dimethylaminobenzaldehyde in ethanol under reflux condition for $6 \mathrm{~h}$, and gave 11-12(a,b) in excellent yields, Scheme 5.

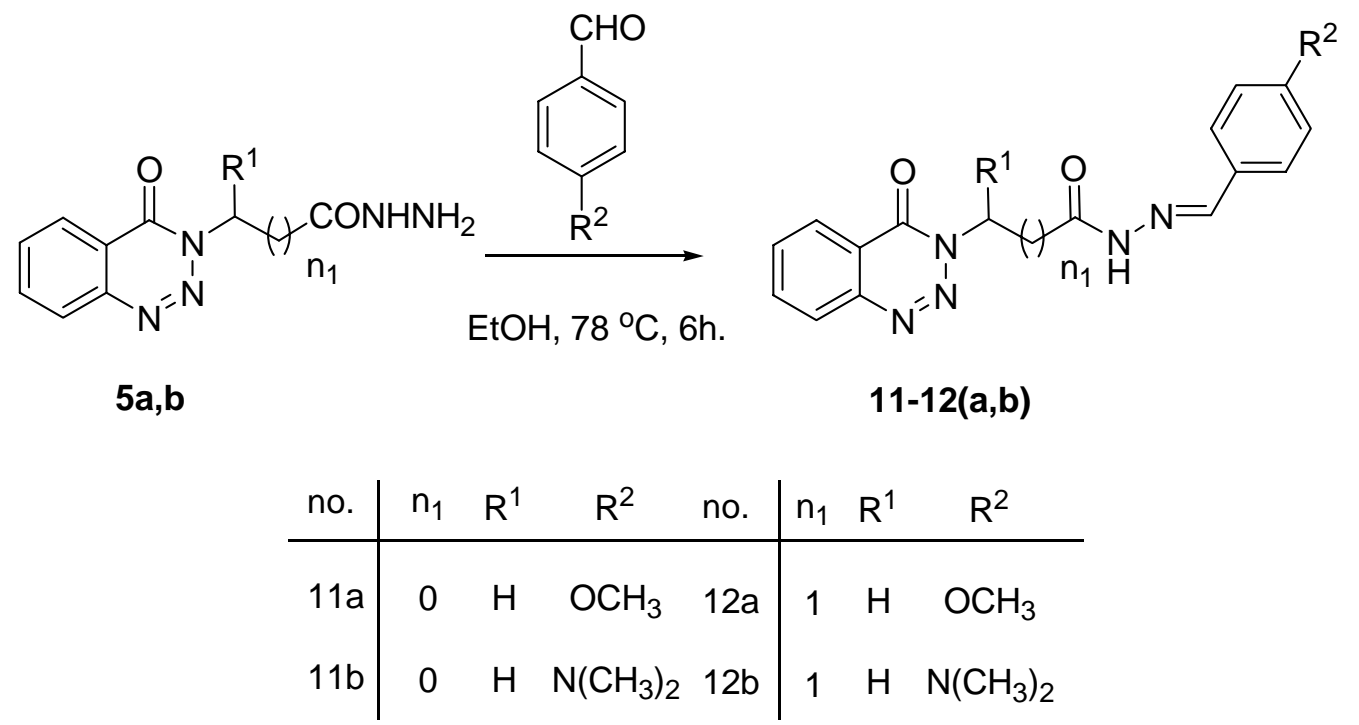

Scheme 5. Condensation of 2-(4-oxobenzotriazin-3(4H)-yl) alkanoic acid hydrazides 5a,b with aldehydes.

Finally, the 2-(4-oxobenzotriazin-3(4H)-yl) acetic acid hydrazide 5a was condensed with arabinose in ethanol under reflux condition for $6 \mathrm{~h}$, and gave 13, Scheme 6.<smiles>CCO[13C](=O)c1ccccc1</smiles>

$5 a$<smiles>O=C(CCn1nnc2ccccc2c1=O)N/N=C(/O)C(O)C(O)C(O)CO</smiles>

Scheme 6. Condensation of 2-(4-oxobenzotriazin-3(4H)-yl) acetic acid hydrazide5a with arabinose. 


\section{3- Biological activity}

\subsection{Introduction for molecular Docking Methodology:}

Bioinformatics including molecular modeling studies are very valuable at the present time in the field of drug discovery, saving money and effort needed for the screening of new compounds by guiding and confining the investigation to possible target/ targets. The use of docking simulation studies in our project is quite important to help in predicting the possible mode of action and structure activity relationship of the active derivatives and guiding the research future directions in compounds optimization and biochemical enzyme assay for the possible target enzymes. Key interactions at protein-protein interfaces constitute important targets for small molecule inhibition because of their specific arrangements and biological importance. ${ }^{20}$

All the molecular modeling studies were carried out on Intel ${ }^{\circledR}$ Core $^{\mathrm{TM}}$ i3 $\mathrm{CPU}, 2.40 \mathrm{GHZ}$ processor, and 3 GB memory with Windows 7 operating system using Molecular Operating Environment (MOE 2008-10 Chemical Computing Group, Canada) as the computational software. Anti-bacterial activities of the synthesized benzotriazinone derivatives were investigated through correlation with E. coli Fab-H inhibitory activities, and the anti-cancer activity of compounds were screened through detection of their ability to act as Vitamin D receptor. The crystal structure of E. coli FabH-CoA complex structure (PDB code: 1HNJ), and the crystal structure of the nuclear receptor for vitamin D bound to its natural ligand (PDB code: 1DB1) were obtained from the freely accessible Protein data bank. The docking studies were performed after the verification process which was performed by redocking of the co crystallized ligand into the active site using the default settings. The synthesized derivatives were docked within the active site of the crystallized structures using the MOE dock tool in MOE, performed with the default values. Different conformers for each compound are imported by systematic conformational of the MOE and saved in an mdb data base file to be docked into the active site of the receptor. Each complex was analyzed for interaction, 2D and 3D images were taken by using MOE visualizing tool.

The results were evaluated based on binding affinity calculation together with cluster size determination and visually through possible interaction with key residues at the active site. 


\subsection{Anti-bacterial activity:}

\subsubsection{Molecular Modeling Study:}

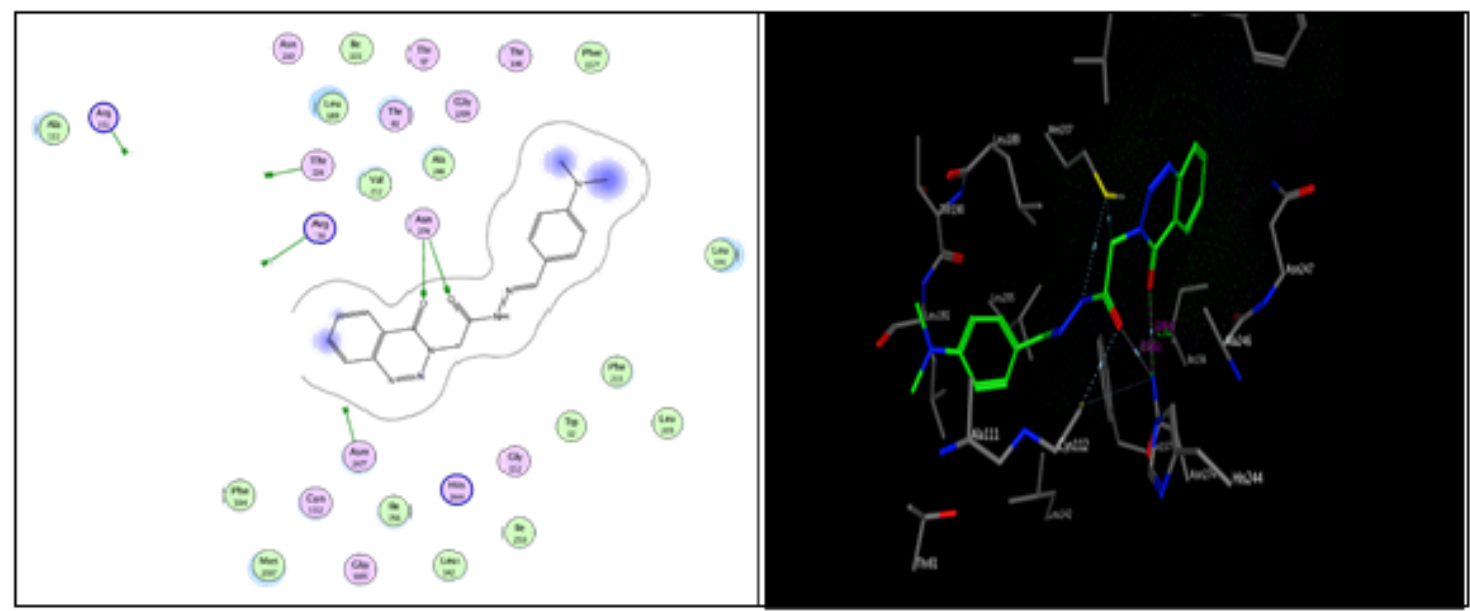

Fig. (2):- Two-dimensional (2-D) and three-dimensional (3-D) interaction ofcompound(11b)

As shown in the figure; compound (11b) formed two hydrogen bonds as sidechain acceptor with amino acid residue Asn274. The amino acid residues Asn 247, Arg 36 and Thr 28 weren't oriented directly to form complete hydrogen bonds with the ligand structure. Moreover, there are four ligand exposure which indicate good binding affinity of the compound with the receptor under study.

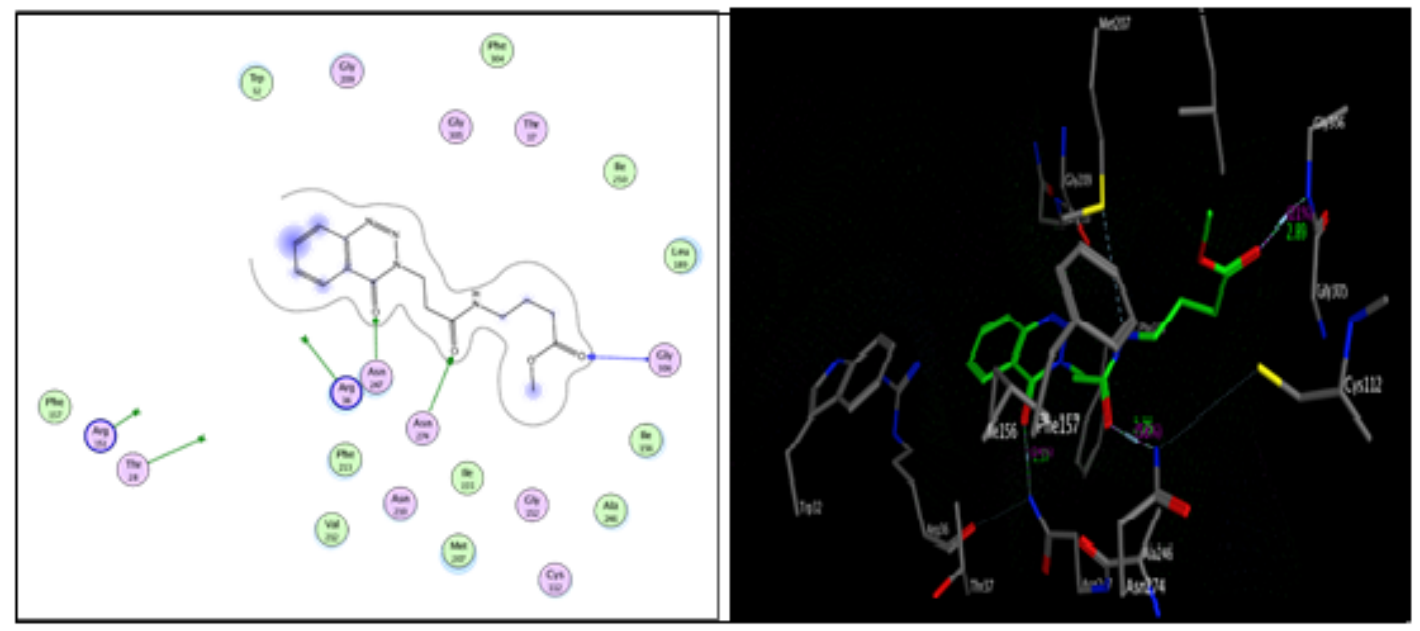

Fig. (3):- Two-dimensional (2-D) and three-dimensional (3-D) interaction ofcompound(10c) 
As shown in the figure; compound (10c)formed two hydrogen bonds as sidechain acceptor with amino acid residue Asn274 and Asn247 in addition to one hydrogen bond as a back-bone acceptor with amino acidresidue Gly 306. However, the amino acid residues Thr 28, Arg 36 and Arg 151 weren't oriented directly to form complete hydrogen bonds with the ligand structure. Moreover, there are ten ligand exposure which indicate good binding affinity of the compound with the receptor under study.

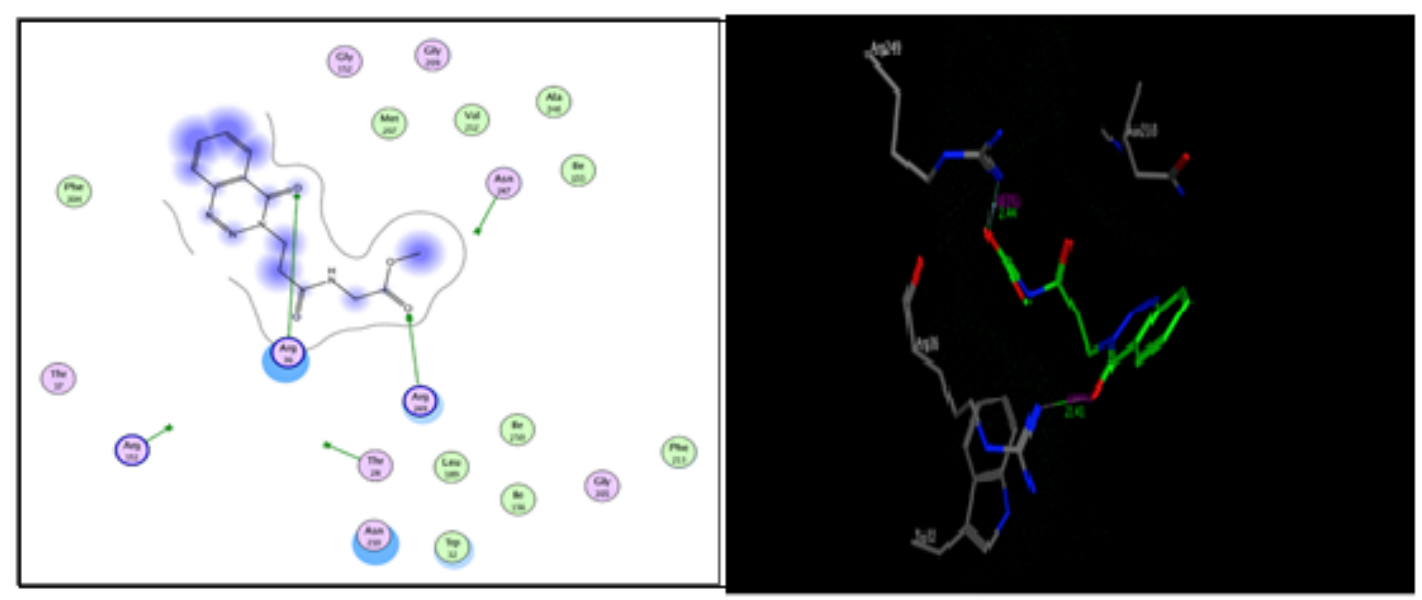

Fig. (4):- Two-dimensional (2-D) and three-dimensional (3-D) interaction of compound (10a)

As shown in the figure; compound (10a) formed two hydrogen bonds as sidechain acceptor with amino acid residue Arg 36 and Arg 249. However, the amino acid residues Thr 28, Arg 151 and Asn 247 weren't oriented directly to form complete hydrogen bonds with the ligand structure. Moreover, there are sixteen ligand exposure which indicate good binding affinity of the compound with the receptor under study.

\subsubsection{In vitro anti-bacterial activity:}

The in vitro antibacterial activity of highest binding affinity docked compounds were tested against E. coli, Staphylococcus aureus and Salmonella spp. All the tested compounds gave effective positive results against E. coli with inhibitory zone of about $1.1 \mathrm{Cm}$, while were inactive against Staphylococcus aureus and Salmonella spp.

\subsection{Anti-cancer activity:}

\subsubsection{Molecular Modeling study:}




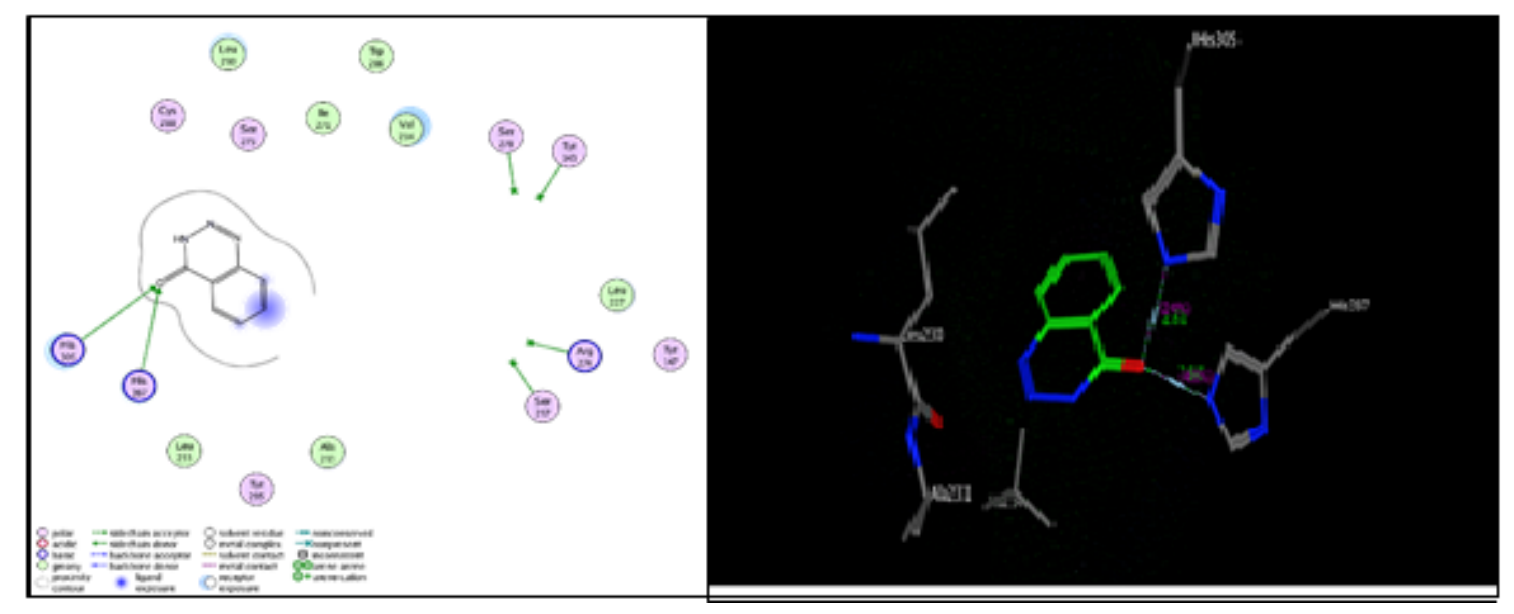

Fig. (5):- Two-dimensional (2-D) and three-dimensional (3-D) interaction of compound (3)

As shown in the figure; compound (3) formed two hydrogen bonds as a side chain acceptor with amino acid residue His 305 and His 379. However the amino acid residues Tyr 143, Ser 237, Arg 274 and Ser 278 weren't oriented directly to form complete hydrogen bonds with the ligand structure. Moreover, there are three ligand exposure which indicate good binding affinity of the compound with the receptor under study.

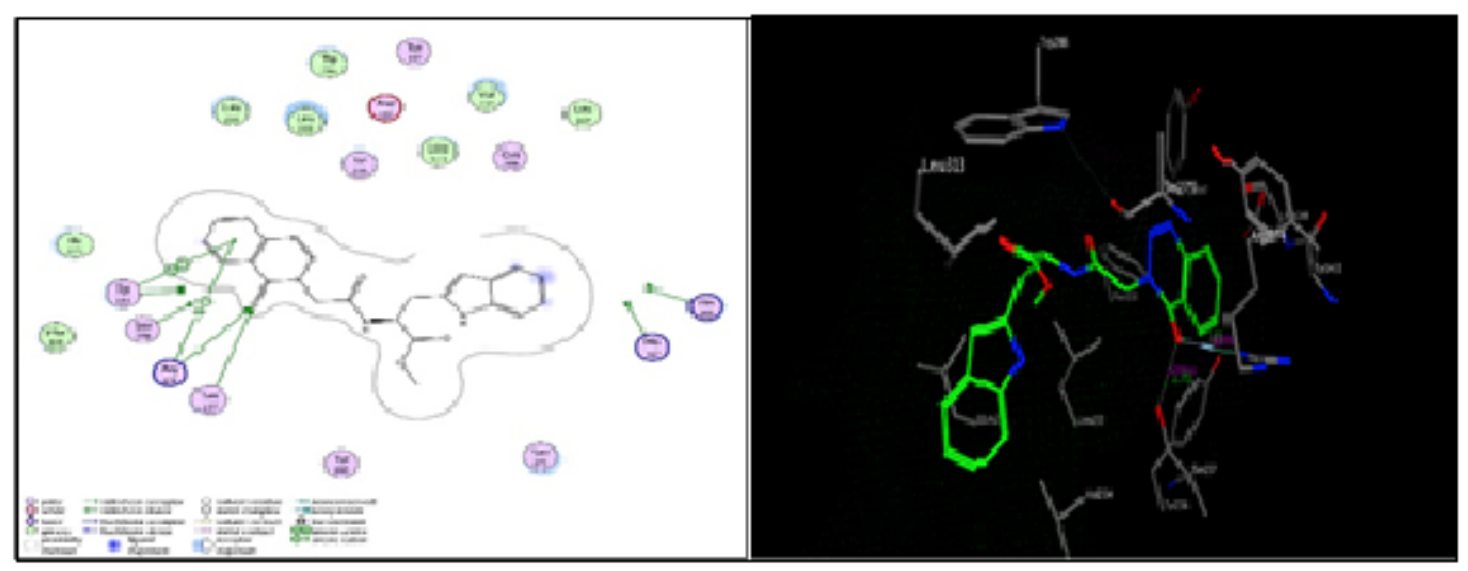

Fig. (6):- Two-dimensional (2-D) and three-dimensional (3-D) interaction of compound (9d)

As shown in the figure; compound (9d) formed two hydrogen bonds as a side chain acceptor with amino acid residue Ser 237 and Arg 274. In addition to one hydrogen bond as arene-cation interaction with amino acid residue Arg 274. Another hydrogen bond formed with amino acidresidue Tyr 143 as arene-arene interaction. However, the amino acid residues Tyr 143, Ser 237, Ser 278, His 305 and His 397 weren't oriented directly to form complete hydrogen bonds 
with the ligand structure. Moreover, there are four ligand exposure which indicate good binding affinity of the compound with the receptor under study.

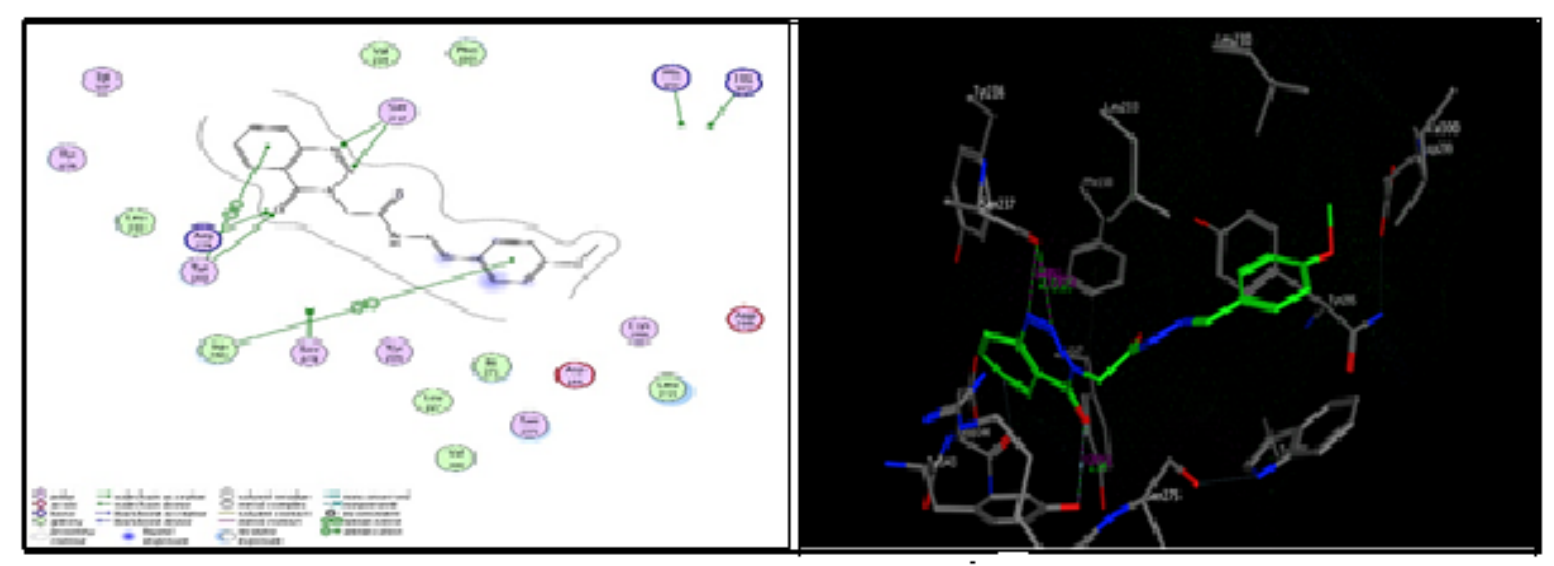

Fig. (7):- Two-dimensional (2-D) and three-dimensional (3-D) interaction of compound (11a)

As shown in the figure; compound (11a) formed two hydrogen bonds with amino acid residue Tyr 143 one of their as a side chain acceptor and the other one as arene-arene interaction. In addition to form two also two hydrogen bonds as a side chain acceptor with the amino acid residue Ser 237. It also formed one hydrogen bond as arene-arene interaction with amino acid residue Trp 286. However, the amino acid residues Arg 274, Ser 278, His 305 and His 397 weren't oriented directly to form complete hydrogen bonds with the ligand structure. Moreover, there are five ligand exposures, which indicate good binding affinity of the compound with the receptor under study.

\subsubsection{In vitro anti-cancer activity:}

Potential cytotoxicity of the newly synthesized compounds was tested against human liver carcinoma cell line (HepG2) using the method of Hansen etal. ${ }^{21,22}$ The in vitro anticancer screening was done by planting tissue unit in vacsera, Cairo A. R. Egypt.

This work was performed by a modification (Hansen et al., 1989) ${ }^{21}$ of the tetrazolium salt (MTT) method Mosmann, 1983. ${ }^{22}$ Preferably, cells should be plated in triplicate wells. Relative cell proliferation/viability was measured when eg- treated cells are compared with untreated cells.

The in vitro cytotoxic activity of the highest binding affinity docked compounds were tested against human liver carcinoma cell line (HepG2) cancer cell lines. Many compounds showed 
potent cytotoxic activity with low $\mathrm{IC}_{50}$ values, especially for $5(6.525 \mu \mathrm{M})$ and $\mathbf{1 3 a}(10.97 \mu \mathrm{M})$, while for standard drug doxorubicin $(5.8 \mu \mathrm{M})$.

\section{4- Acknowledgements}

We would like to thank the Science \& Technology Development Fund in Egypt STDF Project ID: 22909 for funding this research proposal.

\section{References}

1. El-Rayes, S., Gomaa, M.S.,Abouelmagd, A., Fathalla, W., Ali, I.A.I.Synthesis and antiproliferative assay of triazolyl-2,2-dimethyl-3-phenylpropanoates as potential HDAC inhibitors RSC Advances2019, 9(24), 13896.

2. S. M. El Rayes,A. Abo Elmagd,Gomaa M. S., Ibrahim A. I. Ali, Walid Fathalla, Faheem Hyder Pottoo,F. A. KhanConvenient synthesis and antiproliferative activity of methyl 2-[3(3-phenyl-quinoxalin-2-ylsulfanyl)propanamido]alkanoates and N-Alkyl 3-((3phenylquinoxalin-2-yl)sulfanyl) propanamides accepted in ACS Omega 2019DOI 10.1021/acsomega.9b02320

3. G. Sammaiah and M. Sarangapani, Asian J. Chem., 2008, 20, 282.

4. G. Daidone, S. Plescia, D. Raffa, M. Bajardi, M. Matera, A. Caruso, and M. Leone, IlFarmaco, 1990, 45, 391.

5. F. Fiorino, B. Severino, F. De Angelis, E. Perissutti, F. Frecentese, P. Massarelli, G. Bruni, E. Collavoli, V. Santagada, and G. Caliendo, Arch. Pharm., 2008, 341, 20.

6. H. Takai, H. Obase, N. Nakamizo, M. Teranishi, K. Kubo, K. Shuto, and T. Hashimoto, Chem.Pharm. Bull., 1985,33, 1104.

7. F. Fiorino, G. Caliendo, E. Perissutti, B. Severino, F. Frecentese, B. Preziosi, A. A. Izzo, R. Capasso, and V. Santagada, Arch. Pharm., 2005, 338, 548.

8. G. Caliendo, F. Fiorino, P. Grieco, E. Perissutti, V. Santagada, R. Meli, G. M. Raso, A. Zanesco, and G. De Nucci, Eur. J. Med. Chem., 1999, 34, 1043.

9. D. Raffa, G. Daidone, B. Maggio, D. Schillaci, and F. Plescia, Arch. Pharm., 1999, 332, 317.

10. J. V. Jollimore, K. Vaughan, and D. L. Hooper, J. Org. Chem., 1996, 61, 210 
11. D. R. Witty, J. Bateson, G. J. Hervieu, K. Al-Barazanji, P. Jeffrey, D. Hamprecht, A Haynes, C. N. Johnson, A. I. Muir, and P. J. O’Hanlon, Bioorg. Med. Chem. Lett., 2006, 16, 4872

12. . H.H.Rang,M.M.Dale, J.M.Ritter,R.J.Flower and G.Henderson; Rang and Dale, s Pharmacology 7thed, (2012) 673.

13. Kelson, AB; McNamara, JP; Pandey, A; Ryan, KJ; Dorie, MJ; McAfee, PA; Menke, DR; Brown, JM; Tracy, M Anti-Cancer Drug Design, 1998,13, 575.

14. A. Vaisburg, I. Paquin, N. Bernstein, S. Frechette, F. Gaudette, S. Leit, O. Moradei, S. Raeppel, N. Zhou, and G. Bouchain, Bioorg. Med. Chem. Lett., 2007, 17, 6729.

15. Y. Takeuchi and S. Higuchi, Jpn. KokaiTokkyoKoho JP 129046 A 20020509, 2002.

16. T. Ishizaka, H. Okamura, and H. Okada, Jpn. KokaiTokkyoKoho JP 10221808 A $19980821,1998$.

17. A. R. Katritzky, K. Suzuki, and S. K. Singh, ARKIVOC, 2004, i, 12.

18. El Fekki Ismail, Ibrahim A. I. Ali, Walid Fathalla, Amer A. Alsheikh, and El Said El Tamney. Synthesis of methyl [3-alkyl-2-(2,4-dioxo-3,4-dihydro-2H-quinazolin-1-yl)acetamido] alkanoate. Arkivoc 2017, part iv, 104.

19. Mohamed Megahed, Walid Fathalla, Amer Elsheikh. J. Heterocyclic Chem.,2018, 55, 2799.

20. S. Fletcher, A. D. Hamilton, J. R. Soc. Interface, 2006, 3, 215

21. Hansen, M. B., Nielsen, S. E. \& Berg, K. Re-examination and further development of a precise and rapid dye method for measuring cell growth/cell kill. J Immunol Methods1989, 119, 203-10.

22. Mosmann, T. Rapid colorimetric assay for cellular growth and survival: application to proliferation and cytotoxicity assays. J Immunol Methods1983, 65, 55. 